Check for updates

Stanford University, Stanford, CA, USA

jioannid@stanford.edu

Cite this as: $B M J 2020 ; 371: \mathrm{m} 4048$

http://dx.doi.org/10.1136/bmj.m4048

Published: 26 October 2020

\section{Scientific petitions and open letters in the era of covid-19}

\author{
Vote counting is a faulty method of scientific inference, argues John loannidis
}

\author{
John PA loannidis professor
}

Petitions and open letters signed by large numbers of scientists are not new, but they have proliferated in the covid-19 era. ${ }^{12}$ They have a clear role when it comes to questions of ethics, social problems, and injustices. With monumental consequences from both the pandemic and the response to the pandemic, debating ethical and social matters is the right of every citizen, including scientists. A collateral damage, however, is when these documents are aimed to prove or disprove scientific positions.

Scientists may take pride that their advocacy can save lives, mobilise resources for worthy enterprises, or teach leaders and fellow citizens. Petitions often convey a sense of urgency, conviction, and resolution. Petitions may fervently support opposing positions such as being in favour or against measures such as lockdowns or school closures. They may press on matters of transmission (such as whether airborne, aerosol transmission is common) or risk (whether children are at risk, for example). Sometimes, they acquire a component of personal attack, lambasting or supporting government officials for recommendations and actions. Various media further reverberate these documents. Participation of the general public in these debates is welcome, but the bounds of civility are often crossed and many scientists, signatories, or opponents are unjustifiably smeared. Most importantly, however, petitions should not be used to prove that the positions of the signatories are scientifically correct. As has been previously observed, this is a fallacy implying that the larger the number of scientists who sign, the more valid their scientific positions are. ${ }^{34}$ Vote counting is a faulty method of scientific inference. Science is replete with situations where vehement majorities have held wrong beliefs.

Signatory credentials carry little weight for further validating the veracity of petitioned materials. Invoking authority is yet another fallacy. Expert opinions are at the bottom of the evidence hierarchy. Angry, scared, opinionated experts have even less trustworthiness. Over-confident petitions can be embarrassing when the recruited experts do not even cover key dimensions of necessary expertise. Microbiologists and infectious disease experts may not, for example, know enough about diseases of despair, economics, and social meltdown dynamics, and economists may lack knowledge about virology, immunology, or intensive care.

There are other drawbacks in using petitions to prove scientific points. Firstly, absolute knowledge that can be summarised with a few paragraphs or bullet points (an unavoidable feature of letter writing) is almost non-existent across science. Good science is nuanced.
Forced consensus or over-simplification is detrimental.

Secondly, signatories may not fully agree or may even partly disagree with what they co-sign. A survey examining the positions of signatories on a hot topic (denouncing "statistical significance") showed that several had not read the petition, or read it after it was published; many of them held opposite views to several points made by the signed petition, and most had adopted research practices in their recent work that contradicted what they were espousing in the letter. ${ }^{3}$

Thirdly, petitions create covert coercion, stifling academic freedom. When academic leaders encourage their faculty to sign, coercion exists, even if the language of the invitation is relaxed. Younger or more junior faculty members depend on their senior leaders for their academic prospects. Many may compromise to avoid appearing defiant.

Fourthly, petitions create a false sense of certainty during a new pandemic where uncertainty unavoidably exists. ${ }^{5}$ This hinders scientific inquisitiveness. Scientists may feel threatened by the mass mentality expressed by these letters and by the accompanying media smearing; they may self-censor their high risk or unpopular ideas. Challenging orthodoxy is never easy, but it becomes almost impossible when proponents of orthodoxy speak out vehemently about how incontestable their "truth" is.

Fifthly, exaggerated certainty can backfire and damage science at large if some vehemently held positions are refuted downstream by accumulating evidence. The anti-vaccine movement and climate emergency deniers are already drawing ammunition from the reversals of opinion and policy during the pandemic. Clearly the strategy of deniers is inappropriate, since the knowledge we have about covid-19 and how to handle it is still evolving, while we have solid evidence about the efficacy and safety of the measles, mumps, and rubella vaccine or the dangers of climate emergency. Science deniers, however, capitalise on the exaggerations that accompany covid-19-related statements.

Sixthly, petition letters can easily fall prey to political ideology. In a polarised, charged environment, as is typical of the US and many other countries around the world, petitions often reflect the political preferences of the leaders who composed them. This becomes most obvious in attacks against government officials and task force figures. Brilliant scientists such as Anthony Fauci have been ferociously smeared and now need bodyguards. ${ }^{6}$ Even when letter writers have no intention of taking political sides, their petitions may be misused to promote political 
agendas. Mixing science with politics can become damaging.

Finally, many signatories may have conflicts of interest, but these are hardly ever disclosed in the petition format. Conversely, they would have had to disclose these conflicts, if they submitted their views to a scientific journal.

Dealing with the major threat of covid-19 requires the best science and the best environment to foster it: unperturbed academic freedom, without partisanship, with healthy scepticism and with full transparency about potential conflicts. Petitions are a superb advocacy tool. Both scientists and non-scientists may use them for ethical purposes, to advocate for what matters to them. Petitions should not, however, be masqueraded as weapons of scientific argumentation. Scientific truth is not a matter of zealotry and is not decided by the bulk of signatories.

Competing interests: I have no conflicts of interest and I have received no funding for my covid-19 work. I have signed, in the past, open letters and petitions on ethical problems but have declined to sign open letters and petitions that claim to settle scientific matters.

Not commissioned, not peer reviewed.

1 McCook A. Thousands boycott new Nature journal about machine learning. Retraction Watch. 2018. https://retractionwatch.com/2018/05/01/thousands-boycott-new-nature-journal-aboutmachine-learning.

2 Eisen M. Open letter in support of funder open publishing mandates. http://michaeleisen.org/petition.

3 Hardwicke TE, Ioannidis JPA. Petitions in scientific argumentation: dissecting the request to retire statistical significance. Eur J Clin Invest 2019;49:e13162. doi: 10.1111/eci.13162 pmid: 31380567

4 Walton DN. Why is the 'ad Populum' a fallacy?Philos Rhetor 1980;13:264-78.

5 Ioannidis JPA. Coronavirus disease 2019: the harms of exaggerated information and non-evidence-based measures. Eur J Clin Invest 2020;50:e13222. doi: 10.1111/eci.13222 pmid: 32191341

6 Holpuch A. Fauci tells of death threats as Birx pinpoints fresh areas of covid concern. Guardian. 6 August 2020. www.theguardian.com/world/2020/aug/06/anthony-fauci-death-threats-coronavirus. 